\title{
Renal cell carcinoma (RCC): fatter is better? A review on the role of obesity in RCC
}

\author{
Fabio Turco', Marcello Tucci2, Rosario Francesco Di Stefano', Alessandro Samuelly', Maristella Bungaro1, \\ Marco Audisio', Chiara Pisano1, Massimo Di Maio³, Giorgio Vittorio Scagliotti1 and Consuelo Buttigliero \\ 1Department of Oncology, University of Turin, at Division of Medical Oncology, San Luigi Gonzaga Hospital, Orbassano, Turin, Italy \\ 2Medical Oncology Department, Cardinal Massaia Hospital, Asti, Italy \\ 3Department of Oncology, University of Turin, at Division of Medical Oncology, Ordine Mauriziano Hospital, Turin, Italy
}

Correspondence should be addressed to M Tucci: marcello.tucci@gmail.com

\begin{abstract}
Obesity represents a well-known risk factor for renal cell carcinoma development. Several studies evaluated the relationship between obesity and outcome in patients with nonmetastatic and metastatic renal cell carcinoma using different parameters such as BMI, visceral fat area and s.c. fat area. These studies suggest that obesity is associated with a better prognosis in renal cell carcinoma patients. This phenomenon is called obesity paradox and it was found in other diseases in which obesity represents an established risk factor such as heart failure, diabetes, atrial fibrillation, hypertension and coronary heart disease. The purpose of this review is to analyze the mechanisms by which obesity increases the risk of renal cell carcinoma development, to describe the evidence available to date about the link obesity-outcome and to evaluate the mechanisms to explain this apparently paradoxical relationship.
\end{abstract}

\author{
Key Words \\ - renal cell carcinoma \\ - obesity \\ - obesity paradox \\ - tyrosine kinase inhibitors \\ - immune checkpoint \\ inhibitors
}

\section{Introduction}

Renal cell carcinoma (RCC) is the 9th most common cancer in men and the 14th most common cancer in women worldwide (Znaor et al. 2015). It accounts for about $4 \%$ of all new cancer cases and it is the most lethal of the common urological cancers with a 5-year relative survival of $75.2 \%$ (https://seer.cancer.gov/statfacts/html/ kidrp.html November 2020). Surgery is the mainstay of treatment for localized or locally advanced RCC (https:// uroweb.org/guideline/renal-cell-carcinoma/\#7 November 2020). Therapy landscape of metastatic disease has evolved dramatically over the past 15 years (Gong et al. 2016). Since 2005, multiple new drugs have been approved including tyrosine kinase inhibitors (TKIs) and immune checkpoint inhibitors (ICIs). Consequently, the overall survival (OS) of patients with metastatic RCC (mRCC) has increased from 1 year during the cytokine era to approximately
2.5-3 years in the TKIs and immunotherapy era (Gong et al. 2016). Metastatic RCC therapeutic standard is further changing following the results of recent studies showing the superiority of immunotherapy combinations (nivolumab+ipilimumab) and immunotherapy plus TKIs combinations (pembrolizumab+axitinib, avelumab+axitinib, nivolumab+cabozantinib and lenvatinib + pembrolizumab) compared to TKIs monotherapy in the first line (Motzer et al. 2018, 2019, Rini et al. 2019, Choueiri et al. 2021, Motzer et al. 2021). Although major advances have been made in understanding the molecular basis of RCC carcinogenesis, the therapeutic choice is still based on the clinical features of patients. Two risk models, the Memorial Sloan Kettering Cancer Center (MSKCC) and the International Metastatic Renal Cell Carcinoma Database Consortium (IMDC), (c) 2021 Society for Endocrinology Published by Bioscientifica Ltd. Printed in Great Britain 
are commonly used to predict prognosis and guide therapeutic choice (Motzer et al. 2000, Heng et al. 2009). These risk models include clinical and laboratory factors: MSKCC model includes hemoglobin, performance status, time from diagnosis to systemic treatment, calcium and LDH levels while IMDC model includes the first MSKCC four criteria plus neutrophil and platelet count. These models identify three risk categories characterized by different prognosis: favorable (0 risk factors), intermediate (1-2 risk factors) and poor ( $>2$ risk factors).

RCC etiology is still largely unknown. Carcinogenic agents according to International Agency for Research on Cancer (IARC) are tobacco smoking, trichloroethylene, $\mathrm{X}$-radiation and gamma-radiation (Cho et al. 2011). Risk factors for RCC also include hypertension, a family history of RCC and genetic conditions such as von Hippel-Lindau disease, hereditary papillary renal cell carcinoma, hereditary leiomyomatosis and Birt-HoggDube syndrome (Cho et al. 2011). Overweight, especially obesity, is a well-established, modifiable risk factor for the development of several types of cancer in both women and men, including RCC (Bergström et al. 2001, Cho et al. 2011, Davoodi et al. 2013). In 2016, IARC showed that the absence of excess body fat reduces the risk of most cancers including RCC (Lauby-Secretan et al. 2016).

Although obesity represents a strong risk factor for RCC development, several studies have shown that it is associated with a better prognosis than patients with normal weight. The aim of this review is to summarize the evidence currently available regarding the association between obesity and RCC trying to explain what is defined as the obesity paradox: why obesity, which increases the risk of developing RCC, is associated with better outcomes?

\section{Obesity paradox}

In recent years there has been a growing interest in the so-called 'obesity paradox'. Despite the known association between obesity and the onset of some chronic diseases, multiple studies reported that obesity confers better survival. The obesity paradox was first described in 1999 in overweight and patients with obesity undergoing hemodialysis and has subsequently been found in patients with hemodynamic and metabolic disorders such as heart failure, coronary heart disease, atrial fibrillation, hypertension and diabetes (Fleischmann et al. 1999, Uretsky et al. 2007, Carnethon et al. 2012, Sharma et al. 2015, Liu et al. 2020). Several theories have been proposed to explain this paradox. These diseases should be diagnosed earlier in patients with obesity than in normal-weight patients, therefore, they could have an earlier use of treatments (Uretsky et al. 2007, Oreopoulos et al. 2008). Lower BMI values are associated to a negative survival status as sarcopenia and cachexia (Romero-Corral et al. 2006, Oreopoulos et al. 2008, Sharma et al. 2015). In addition, patients with obesity have some cardiovascular protective factors: lower levels of brain natriuretic peptide (BNP) and N-terminal pro b-type natriuretic peptide (NTproBNP), reduced activation of sympathetic nervous system and renin-angiotensin system (RAA) (Oreopoulos et al. 2008). Furthermore, the adipocytes produce the receptor for tumor necrosis factor-alpha (TNFa) which neutralizes cardiotoxic effects of TNFa (negative inotropic effect and arrhythmogenic factor) (Uretsky et al. 2007, Oreopoulos et al. 2008). The abundance of adipose tissue could eventually counteract the negative effects of catabolic state in patients with chronic renal failure or heath failure, thus improving their prognosis (Oreopoulos et al. 2008).

The obesity paradox has also been investigated in different cancer settings. Greenlee et al. suggest that the association between BMI and cancer survival is not consistent across all cancer types (Greenlee et al. 2017). One of the cancers in which the obesity paradox has been extensively studied is RCC. In RCC, obesity represents a validated risk factor, but at the same time, it seems to be a positive prognostic factor. Studies evaluating the obesity paradox in RCC used several parameters to define the obesity state. The most used parameter is BMI, defined as weight divided by the square of the body height. BMI is universally expressed in units of $\mathrm{kg} / \mathrm{m}^{2}$, resulting from mass in kilograms and height in meters. Overweight is defined as a BMI of 25 to $29.9 \mathrm{~kg} / \mathrm{m}^{2}$ (23-25 kg/m² in Asian populations) while obesity is defined as a BMI of $30 \mathrm{~kg} / \mathrm{m}^{2}$ or greater $\left(25 \mathrm{~kg} / \mathrm{m}^{2}\right.$ or greater in Asian populations) (https://www.euro.who.int/en/healthtopics/disease-prevention/nutrition/a-healthy-lifestyle/ body-mass-index-bmi; accessed November 2020). Other parameters investigated are s.c. fat area (SFA) and visceral fat area (VFA) measured at the level of the umbilicus using standard CT scans (Tokunaga et al. 1983). Body fat tissue is traditionally distributed in two compartments: s.c. and visceral adipose tissue. Subcutaneous adipose tissue is the fat tissue between the skin and muscle, whereas visceral adipose tissue is allocated within the main cavities of the body, primarily in the abdominal cavity (Mittal 2019). BMI, VFA and SFA are different and not always concordant parameters in defining obesity. BMI is a convenient 
measure but could not indicate the differences among body fat, muscle and bone mass, consequently, skeletal muscle and adipose tissue areas vary widely in patients with the same BMI (Antoun et al. 2014). In addition, BMI also fails to display the distribution of fat (s.c. and visceral) among individuals. Moreover, VFA and SFA could be a more sensitive parameter to estimate nutritional status than BMI (Dai et al. 2020).

\section{Obesity as a risk factor for RCC}

It has been estimated that approximately $25 \%$ of RCC could be attributed to overweight and obesity (Scelo \& Larose 2018); obesity confers a 1.5-2.5 relative risk increase in developing RCC (Calle \& Kaaks 2004). A meta-analysis including 17 epidemiological studies estimated that there is $24 \%$ increase in the risk of developing RCC in men and $34 \%$ in women for each 5-point increase in BMI (Renehan et al. 2008). The mechanisms that link excess weight and cancer risk are not fully understood. White adipose tissue is a complex cellular system including different cells in addition to adipocytes, such as adipose stromal cells, B and $\mathrm{T}$ lymphocytes, macrophages, neutrophils, dendritic cells and mast cells. These cells produce proactive substances which are involved in the regulation of signaling pathways promoting carcinogenesis and leading to an increase in cell proliferation, survival, and angiogenesis (Aurilio et al. 2019). Obesity is associated with an increased risk of developing insulin resistance and type 2 diabetes, which lead to elevated blood levels of insulin-like growth factor- 1 (IGF1) and blood insulin. These hormones cause the activation of the insulin receptors (INSR) and IGF1 receptors (IGF1R) triggering transduction pathways such PI3K/AKT, mTOR/cyclin D1, mTOR/HIF1A/VEGF and Ras which able to promote proliferation, angiogenesis and reduce apoptosis (Calle \& Kaaks 2004, Hursting \& Dunlap 2012, Stone et al. 2018, Aurilio et al. 2019). Moreover, patients with obesity have high levels of the hormone leptin, a potent stimulator of cell proliferation and tumor growth by involving MAPK, Jak/Stat, and PI3K/AKT pathways (Hursting \& Dunlap 2012, Stone et al. 2018, Aurilio et al. 2019). On the other hand, adiponectin, whose concentrations are significantly lower in individuals with obesity compared to normal-weight subjects, through its ADIPOR1 and ADIPOR2 receptors, has an anti-TOR effect, thus inhibiting the angiogenesis process (Gao et al. 2015, Stone et al. 2018, Aurilio et al. 2019). Furthermore, patients with obesity exhibit high levels of ceruloplasmin that is involved in angiogenesis through interaction with its SLC31A1 receptor that induces VEGF production (Stone et al. 2018, Aurilio et al. 2019). Obesity is associated with chronic inflammation favoring tumor initiation and progression, largely through the generation of pro-inflammatory cytokines, in particular TNFa and IL6. These trigger the production of cyclooxygenase 2, which in turn produces prostaglandin E2, favoring cancer progression. TNFa has anti-apoptotic potential through the stimulation of nuclear factor kb (NFkb). The complex IL6/IL6 receptor has an anti-apoptotic and proliferative mechanism through its action via the Janus kinase 2 (Jak 2) signaling pathway. In addition, IL6 induces the PI3K/AKT pathway, which results in the enhancement of cancer cell proliferation and anti-apoptotic effects (Hursting \& Dunlap 2012, Stone et al. 2018, Aurilio et al. 2019).

\section{Obesity as a prognostic factor for RCC}

Several studies show that obesity is linked to better outcomes compared to normal weight both in nonmetastatic (nmRCC) and mRCC patients. In a large Korean cohort study of 1543 patients with nmRCC, Choi et al. found that patients with a BMI $\geq 25$ had a $53 \%$ lower risk of dying from RCC compared to patients with a BMI $<25$. The authors also performed a meta-analysis of 20 studies assessing the link between BMI and outcome in patients with nmRCC and further confirmed that having an increased BMI is associated with better results (41\% lower risk of death from RCC in patients with a high BMI than in patients with a normal BMI) (Choi et al. 2013). This metaanalysis also showed that patients with obesity had better overall survival (HR 0.57 (0.43-0.76)) and recurrencefree survival (RFS) (HR 0.49 (0.30-0.81)) compared to non-obese patients. Instead, there are conflicting results regarding the relationship between SFA/VFA and outcome in patients with nmRCC. Mano et al. showed that SFA and VFA were not associated with OS in 201 patients with nmRCC (HR $0.72(0.5-1.05), P=0.091$ and HR 0.82 (0.49-1.36), $P=0.0446$, respectively) while Naya et al. found that increased VFA in 117 patients was an independent prognostic factor of better survival $(P=0.0257)$ (Naya et al. 2010, Mano et al. 2014). In Kaneko's study, VFA was an independent predictor of better RFS in 285 patients with localized RCC ( $P=0.037)$ (Kaneko et al. 2015) (Table 1).

Several retrospective studies examined the prognostic role of obesity in patients with mRCC undergoing systemic therapy including both TKIs and immunotherapy. Albiges and collaborators found that a BMI $>25$ may be a prognostic factor of better survival in two cohorts of patients $(n=6632)$ who received TKIs, both in first- and second-line settings (HR 0.84 (0.73-0.95) 
Table 1 Obesity biomarkers in non metastatic renal cell carcinoma.

\begin{tabular}{|c|c|c|c|c|c|c|c|c|}
\hline $\begin{array}{l}\text { First author } \\
\text { (year) }\end{array}$ & Trial design & $\begin{array}{l}\text { Sample } \\
\text { size }\end{array}$ & $\begin{array}{l}\text { Obesity } \\
\text { biomarkers }\end{array}$ & Gender & Ethnicity/race & Histology & $\begin{array}{l}\text { Fuhrman } \\
\text { grade }\end{array}$ & Results \\
\hline Choi (2012) & $\mathrm{R}$ & 1543 & $\mathrm{BMI}$ & $\begin{array}{l}\text { Female } 29.4 \% \\
\text { Male } 70.6 \%\end{array}$ & Asian & $\begin{array}{l}\text { Clear cell } \\
84.7 \% \\
\text { Non clear } \\
\text { cell } 15.3 \%\end{array}$ & $\begin{array}{l}\text { G1-2 } 48.3 \% \\
\text { G3-4 51.7\% }\end{array}$ & $\begin{array}{c}\text { OS: HR } 0.45 \\
(0.29-0.68) \\
P<0.001 \\
\text { CSS: HR 0.47 } \\
(0.29-0.77) \\
P<0.001\end{array}$ \\
\hline Choi (2012) & Meta-analysis & 16,089 & BMI & NA & NA & NA & NA & $\begin{array}{r}\text { OS: HR } 0.57 \\
(0.43-0.76) ; \\
\text { CSS: HR 0.59 } \\
(0.48-0.74) ; \\
\text { RFS: HR 0.49 } \\
(0.30-0.81)\end{array}$ \\
\hline $\begin{array}{l}\text { Mano } \\
\quad(2014)\end{array}$ & $\mathrm{R}$ & 201 & SFA and VFA & $\begin{array}{l}\text { Female } 25 \% \\
\text { Male } 75 \%\end{array}$ & $\begin{array}{l}\text { White } 90.5 \% \\
\text { Other } 9.5 \%\end{array}$ & $\begin{array}{l}\text { Clear } \\
\text { cell 100\% }\end{array}$ & $\begin{array}{l}\text { G1-2 } 42.3 \% \\
\text { G3-4 57.7\% }\end{array}$ & $\begin{array}{l}\text { No intererence in } \\
\text { OS; } \\
\text { SFA: HR 0.72 } \\
(0.5-1.05), \\
P=0.091 ; \\
\text { VFA: HR 0.82 } \\
(0.49-1.36), \\
P=0.0446\end{array}$ \\
\hline $\begin{array}{l}\text { Naya } \\
(2010)\end{array}$ & $\mathrm{R}$ & 117 & VFA & Male 100\% & Asian & $\begin{array}{c}\text { Clear cell } \\
100 \%\end{array}$ & $\begin{array}{l}\text { G1-2 79.5\% } \\
\text { G3-4 20.5\% }\end{array}$ & $\begin{array}{c}\text { Improved OS, } \\
P=0.0257\end{array}$ \\
\hline $\begin{array}{r}\text { Kaneko } \\
(2015)\end{array}$ & $\mathrm{R}$ & 285 & VFA & $\begin{array}{l}\text { Female } 19.6 \% \\
\text { Male } 80.5 \%\end{array}$ & Asian & $\begin{array}{l}\text { Clear cell } \\
84.6 \% \\
\text { Non clear } \\
\text { cell } 15.4 \%\end{array}$ & $\begin{array}{l}\text { G1-2 90.5\% } \\
\text { G3-4 9.5\% }\end{array}$ & $\begin{array}{l}\text { Improved RFS, } \\
P=0.037\end{array}$ \\
\hline
\end{tabular}

BMI, body mass index; CSS, cancer-specific survival; NA, not available; OS, overall survival; R, retrospective; RFS, recurrence free survival; SFA, subcutaneous fat area; VFA, visceral fat area.

and $0.83(0.74-0.93)$ in the two cohorts, respectively) (Albiges et al. 2016). In Choueiri's study, obesity is an independent factor for better OS in 475 patients who received sunitinib or sorafenib (median OS 32.5 vs 20.6 months, $P=0.0001$ ) (Choueiri et al. 2010). In a recent study, Sanchez et al. investigated the association between patient survival and transcriptomic profiles of the primary tumor and peritumoral adipose tissue. They analyzed 478 patients with a BMI > 30 from three independent clinical cohorts of patients with RCC: COMPARZ trial $(n=256)$, The Cancer Genome Atlas (TCGA, $n=93)$ and MSK immunotherapy $(n=129)$. OS was significantly longer in patients with obesity than in those with normal weight treated with sunitinib or pazopanib in COMPARZ (adjusted HR $0.68(0.48-0.96)$ ) and TCGA (adjusted HR $0.41(0.22-0.75))$ cohorts even after adjustment for IMDC criteria (Sanchez et al. 2020). Bergerot et al. evaluated the link between overweight outcomes in 353 patients treated with TKIs or ICIs. Among patients treated with TKI with BMI $<25(n=72)$, median OS was 24 months (20.7-27.2) vs 36 months (18.6-53.3) among patients with BMI > $25(n=157)(P=0.02)$ (Bergerot et al. 2019). Instead in Steffens' study, BMI was not significantly associated with PFS $(P=0.63)$ or OS $(P=0.61)$ in 116 patients treated with
TKIs while VFA and SFA were associated with better PFS $(P=0.005 P=0.04)$ and $\mathrm{OS}(P=0.04 P=0.01)$. (Steffens et al. 2011). Mizuno et al. failed to show any association between BMI and PFS $(P=0.2887)$ or OS $(P=0.4476)$ in 114 patients treated with TKIs. However, in this study, a high VFA was found to be a predictive factor for better PFS $(P=0.0070)$ and OS ( $P=0.0001)$ (Mizuno et al. 2017). Gu et al. found that the radiologic measurement of VFA and SFA was independently associated with OS in 124 patients treated with TKIs (HR 0.981, $P=0.002$ and HR 0.987, $P=0.048$, respectively) ( $\mathrm{Gu}$ et al. 2015). These results are directly in contrast to those published by Ladoire who described that, in 64 patients treated with first-line antiangiogenic agents, a high SFA and VFA are predictive biomarkers for shorter PFS $(P=0.048$ and $P=0.0009$, respectively) and OS ( $P=0.0203$ and $P=0.0003$, respectively) (Ladoire et al. 2011). The association between BMI and outcomes was also evaluated in a prospective study; Goebell et al. showed a significant and independent correlation of a BMI $<24$ with shorter OS $(\mathrm{HR}=1.94(1.48-2.54))$ in 606 mRCC patients treated with systemic therapies (in particular TKIs) (Goebell et al. 2018).

The obesity-outcomes link was also assessed in patients with mRCC treated with immunotherapy. In this regard, (c) 2021 Society for Endocrinology Published by Bioscientifica Ltd. Printed in Great Britain 
a non-peer-reviewed abstract by Lalani et al. showed that in 147 patients treated with immunotherapy alone or in combination with TKIs, a BMI $>25$ is associated with OS improvement $(P=0.016)$ while only a non-significant trend was found for PFS. Interestingly, patients who presented a BMI reduction during immunotherapy from $>25$ to $<25$ had shorter OS than patients with no BMI changes ( $\mathrm{HR}=2.25$ (0.94-5.35)) (Lalani et al. 2019). In a study of 90 mRCC patients treated with ICIs, Labadie et al. evaluated the correlation between a series of clinical variables and the response to immunotherapy treatment. In patients with clinical benefit from ICIs $(n=52)$ increased BMI $(P=0.007)$ and overweight BMI status $(P=0.03)$ correlated with improved PFS and OS, respectively (Labadie et al. 2019). De Giorgi found that a BMI $<25$ is significantly associated with worse OS (HR=1.59 (1.10-2.30), $P=0.01)$ in 313 patients treated with Nivolumab progressing after prior antiangiogenic therapy. Furthermore, in this study, the authors demonstrated that patients with BMI $<25$ and a high immune inflammation index (a combination of neutrophils, platelets and lymphocytes) had the worst prognosis $(\mathrm{HR}=3.37$ (2.29-4.95), $P<0.0001$ ) (De Giorgi et al. 2019). Sanchez et al. showed that the inverse association between BMI and OS was not significant after adjustment for IMDC risk score in the MSK immunotherapy cohort (adjusted HR=0.72 (0.40-1.30)) (Sanchez et al. 2020). Similarly, in the subgroup of patients in the Bergerot study who had received immunotherapy $(n=42)$, a non-statistically significant difference in OS was found in favor of patients who had a BMI $<25$ compared to those who had a BMI > 25 (mOS 23.6 vs 19.9 months, $P=0.26$ ) (Bergerot et al. 2019). The obesity paradox in ICIstreated mRCC patients was not demonstrated in the study by Boi et al. $(n=72)$ in which patients with obesity had lower PFS (HR $0.54(0.31-0.95), P=0.0322)$ and OS (HR $0.48(0.24-0.96), P=0.0371)$ than non-obese patients (Boi et al. 2020). The obesity-outcomes relationship in patients treated with immunotherapy has also been evaluated in other types of cancers; Xu et al. performed a meta-analysis to evaluate the overweight impact on survival in 4090 patients with different cancer (mainly melanoma and non-small cell lung cancer) treated with ICIs. It was found that $\mathrm{BMI}>25$ improved $\mathrm{OS}(\mathrm{HR}=0.72(0.51-1.02) ; P=0.06)$ and PFS (HR=0.67 (0.48-0.95); $P=0.02)$. OS improvement was independent of cancer type except for RCC: three studies (424 patients in total) reported the relationship between high BMI and survival of patients with mRCC with contradictory results (Xu et al. 2019) (Table 2). To date, no study has evaluated the role of VFA and SFA in patients with mRCC who received immunotherapy.
The mechanism by which obesity improves the survival of patients with nmRCC and mRCC is not well understood. Patients with higher BMI may adequately preserve their fat and muscle mass, thus allowing a better nutritional status and potential survival advantage delaying the onset of cachexia (Choi et al. 2013). Another possible explanation is that tumors arising in nmRCC patients with obesity may be more indolent than those in normal-weight patients; patients with obesity have favorable clinical and pathologic conditions at diagnosis when compared with normal-weight patients (lower stage, lower Fuhrman grade, smaller tumor size and absence of symptoms and distant metastasis). Although patients with obesity are characterized by a higher rate of tumor growth, they may have more indolent tumors probably because they may be diagnosed at earlier stages as they are at a higher likelihood of being screened for other diseases (Choi et al. 2013). However, Hakimi et al. showed that BMI is inversely associated with advanced stage, regardless of earlier detection during assessments for other comorbidities (hypertension, hypercholesterolemia or diabetes). In this study the association between BMI and better outcomes was attenuated and became nonsignificant when controlling for stage and grade (Hakimi et al. 2013); instead in Choi's study, the association between obesity and better prognosis remained highly significant despite the adjustment for classic risk factors (stage, grade, tumor size and presence of symptoms) (Choi et al. 2013). An alternative explanation for the obesity paradox may be a different gene expression involving fatty acid metabolism genes. FASN (fatty acid synthase) is a gene that regulates de novo biosynthesis of fatty acids, an essential process for tumor growth. FASN is downregulated in patients with obesity and higher FASN expression is associated with worse survival (median 15 vs 36.8 months; $P=0.002$ ) (Horiguchi et al. 2008a, Hakimi et al. 2013, Albiges et al. 2016). An upregulation of FASN gives cancer cells a survival advantage, making it a potential metabolic oncogene (Menendez \& Lupu 2007). In pre-clinical models, it has been shown that the pharmacological inhibition of FASN is able to induce a significant reduction of renal tumor cell growth in vitro (Horiguchi et al. 2008b). Lastly, obese and normal-weight patients could have different transcriptomic profiles. Sanchez et al. showed that tumors of patients with obesity have a different molecular profile comparing with those of normal-weight patients. The molecular profile of obese tumors is characterized by the upregulation of genes associated with hypoxia, angiogenesis and epithelial-mesenchymal transition (Sanchez et al. 2020). 

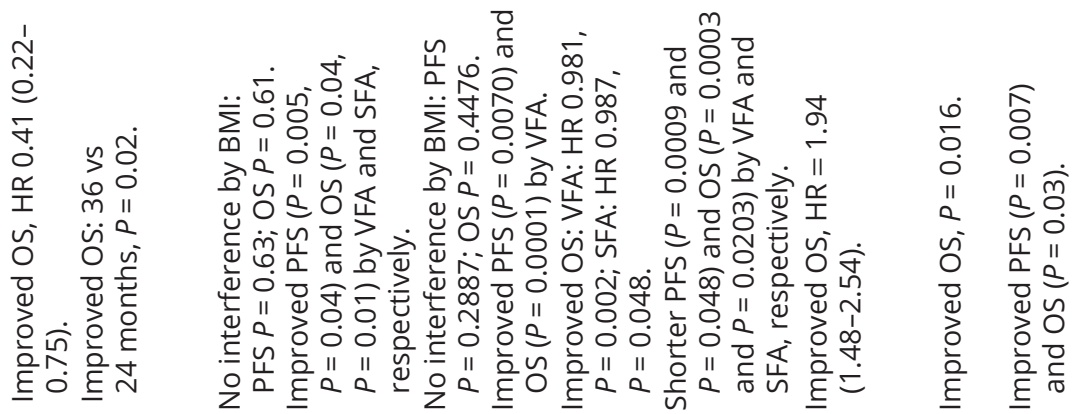

늘 흘

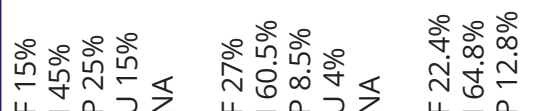

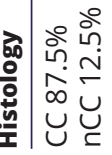

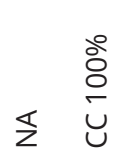

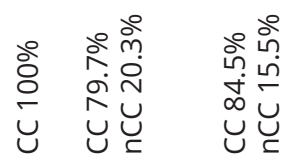

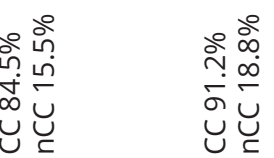

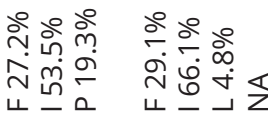

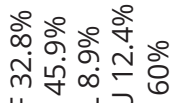

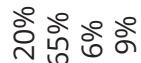

¿

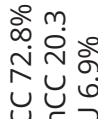

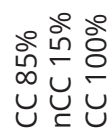
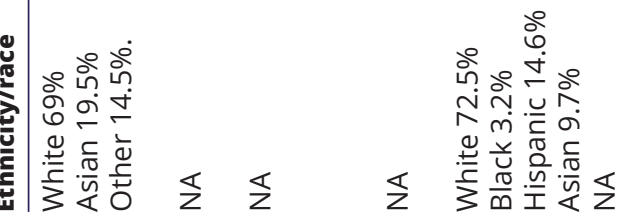

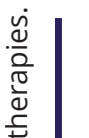

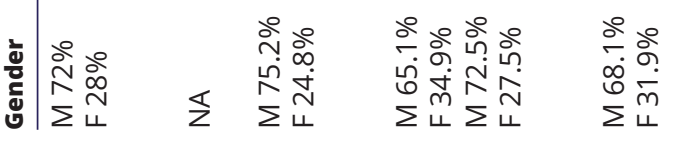

$\cup \subseteq \supset$

.

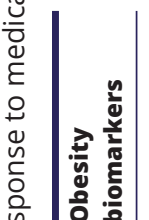

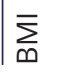

$\sum_{\infty} \sum_{\infty}$

$\sum_{\infty} \sum_{\infty}$

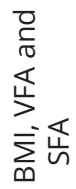

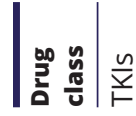

$\stackrel{n}{\stackrel{n}{r}} \stackrel{n}{r}$

$\stackrel{n}{r} \quad \frac{n}{r}$

$\stackrel{n}{r}$

n $\stackrel{m}{m} \stackrel{0}{=}$

$\propto \propto$

$\propto \propto$

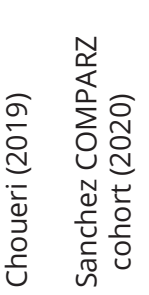

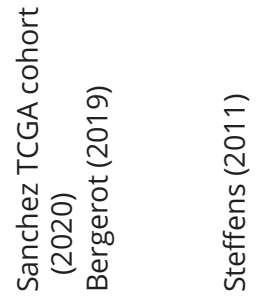

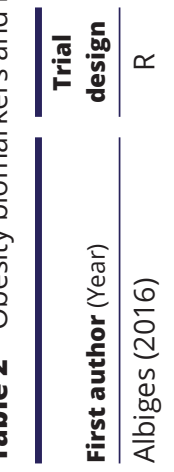

https://erc.bioscientifica.com

https://doi.org/10.1530/ERC-20-0457

(c) 2021 Society for Endocrinology Published by Bioscientifica Ltd.
Printed in Great Britain

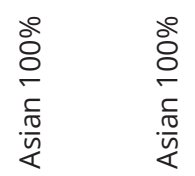

号

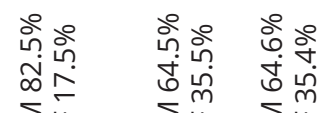

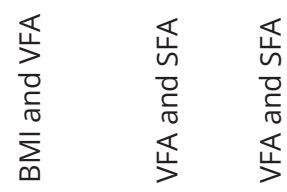

$\sum_{\infty} \quad \sum_{\infty} \sum_{\infty}$

$\stackrel{n}{\square} \quad \frac{n}{F} \quad \frac{n}{F}$

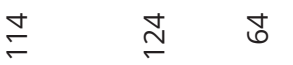

ㅇ ‡

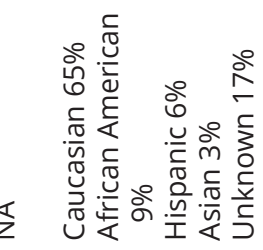

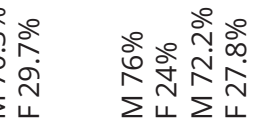

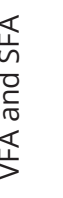

$\stackrel{n}{\underline{r}} \quad \stackrel{+\frac{\omega}{x}}{\underline{\underline{U}}} \underline{\underline{U}}$
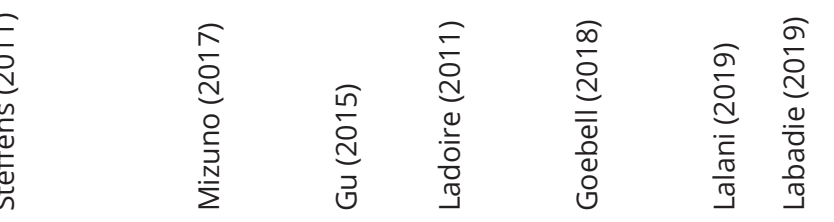

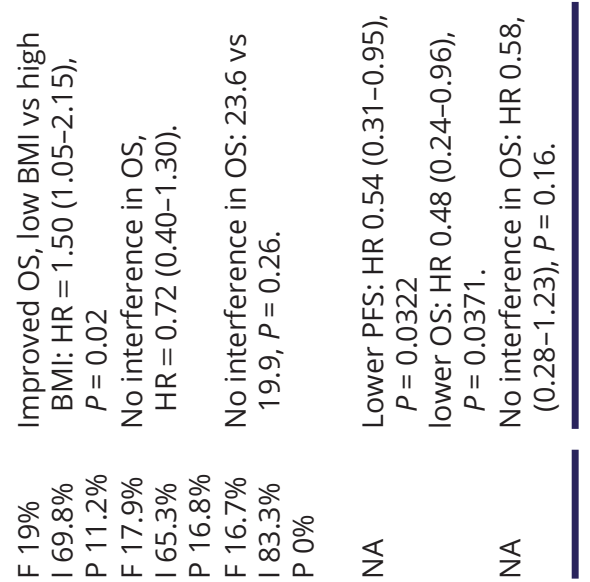

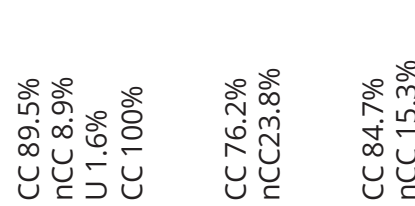
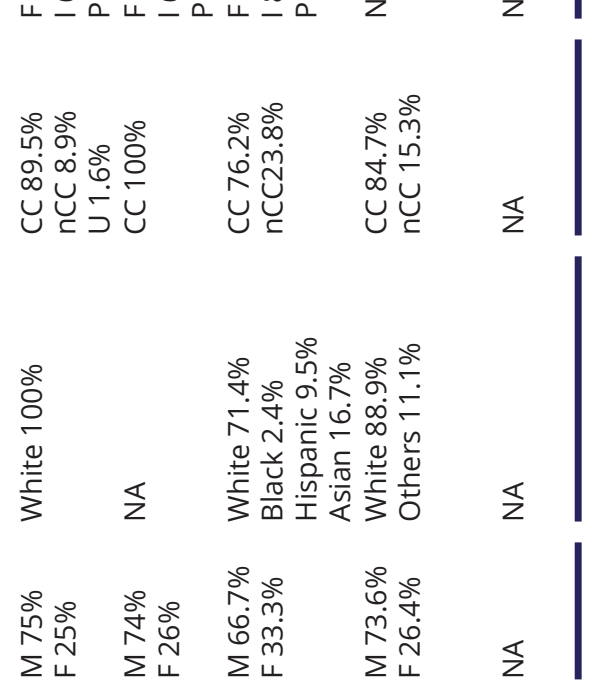

$\frac{10}{4}$

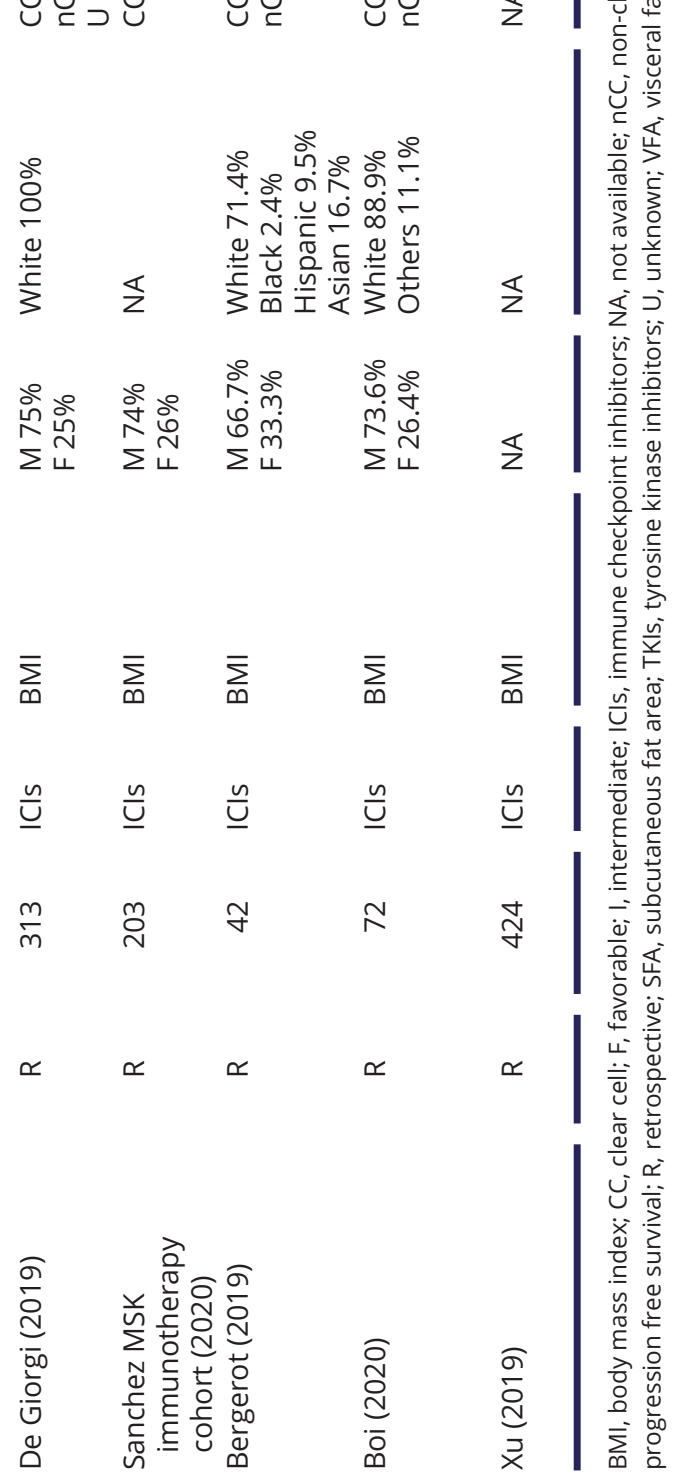

(c) 2021 Society for Endocrinology Published by Bioscientifica Ltd. Printed in Great Britain
Visceral adiposity may create regions of hypoxia, which promotes angiogenesis and tumor microenvironment alterations regulating RCC proliferation. The upregulation of angiogenesis in RCC might explain the increased susceptibility of these tumors to TKIs while it is not clear how these results explain the better outcomes of patients treated with ICIs (Gan \& Heng 2020). No differences were observed in the overall immune infiltration or tumor mutational burden (TMB) in the primary tumors between obese and normal-weight patients (Sanchez et al. 2020). Even in COMPARZ cohort, there was a lower expression of immune checkpoint molecules, as PDL1 (programmed death ligand 1) in obese patients (Sanchez et al. 2020).

These results are in contrast with Wang's study that explored connections between obesity, leptin pathway and PD1 (programmed cell death protein 1) expression on $\mathrm{T}$ cells in a pre-clinical model of melanoma and found that obesity increases T-cell aging resulting in a higher PD1 expression and dysfunction which could be driven, at least in part, by leptin signaling. The PD1-mediated T cell dysfunction in obesity could explain better outcomes for patients with obesity treated with ICIs (Wang et al. 2019). However, these results were not confirmed by Khojandi et al. that found no associations between BMI, leptin levels and PD1 expression on CD8+tumorinfiltrating lymphocytes in a mixed cohort of melanoma and breast cancer patients (Khojandi et al. 2021).

Sanchez et al. also found that in the peritumoral fat of patients with obesity there was a greater infiltration of immune cells and a greater level of hypoxia (Sanchez et al. 2020). Peritumoral adipose tissue might act as a reservoir of immune cells that increases antitumor immune response in the presence of ICIs (Gan \& Heng 2020).

\section{Discussion}

Obesity enhances the risk of developing RCC and at the same time appears to be a factor that increases the survival of both nmRCC and mRCC patients regardless of the treatments performed. This phenomenon is called 'obesity paradox', a phenomenon that has also been demonstrated in other chronic diseases where obesity is a risk factor. The mechanisms that could explain this paradoxical relationship are the presence of a better nutritional status, more indolent tumors, different gene expression and molecular profile of patients with obesity compared to normal-weight patients.

Multiple studies showed that obesity is a prognostic factor in nmRCC. Patients with a high BMI had better OS, RFS, and cancer-specific survival than patients with a 
low BMI. However, these studies have crucial limitations. All the trials, except one, are retrospective. All the studies described have evaluated outcomes between patients with high BMI vs patients with normal and low BMI. Since sarcopenia and cachexia have been described as possible mechanisms that could explain the obesity paradox, it would be useful to know whether the relationship between obesity and better outcomes is confirmed by excluding patients with a low BMI. The studies that analyzed the link between BMI and outcomes in patients with RCC have another important limitation which is represented by the BMI cutpoint used to define the patient as obese; in fact, in some studies the patients were defined as obese with a BMI $>25$ rather than $>30$.

Moreover, using BMI as a surrogate marker for adiposity has limitations due to its imprecise measure of body composition. In particular, BMI might fail to identify sarcopenic obesity, a condition of concomitant highfat body mass and low muscle mass, which represents a worse prognostic factor for cancer patients. Compared to BMI, radiological detection of VFA or SFA might be more accurate in the definition of body composition. We have conflicting data about the association between VFA and SFA with outcomes in nmRCC patients. In particular, in one study, there was no correlation between VFA and SFA with OS while two other studies showed better OS and RFS in patients with high VFA.

The role of obesity as a prognostic factor in MRCC is still an open and intriguing question. BMI appears to be associated with better OS in TKIs-treated patients while its role in immunotherapy-treated patients is less defined. VFA and SFA also appear to be positive prognostic factors in terms of PFS and OS in patients treated with TKIs, while no studies have ever evaluated them in patients treated with ICIs. Another open question is whether weight changes during therapy can influence prognosis or treatment effectiveness. To date, only Lalani et al. found that BMI reductions are associated with worse outcomes in patients treated with immunotherapy (Lalani et al. 2019). Therefore, although the available data seem to show an association between obesity and outcomes in RCC, the crucial limitations described point to a more complex relationship.

The lack of validated predictive factors of treatment response which able to guide oncological decision-making is still an unsolved and challenging issue in mRCC. Currently, treatment decision in patients with mRCC is based on the clinical and biochemical criteria of MSKCC and IMDC. These prognostic scores were developed in an era where nephrectomy and cytokines were the only treatment options. The MSKCC and IMDC criteria have been validated in patients treated with TKIs (Tanaka et al. 2016), nonetheless, whether the same prognostic factors are still relevant for patients treated with immunotherapy remain unclear. Patients treated with ICI may require specific risk stratification given the unique mechanism of action of immunotherapy. Martini et al. elaborated a new risk scoring system in a retrospective analysis of 100 patients. This model includes monocyte-to-lymphocyte ratio (MLR), number and sites of metastases and BMI. It identifies poor-risk patients (BMI $\leq 24$, metastases $>2$ with liver metastases, and MLR > 0.93) and good-risk patients (BMI $>24$, MLR $<0.93$, and metastases $<2$ ); in poorrisk patients, both OS $(P=0.002)$ and PFS $(P=0.03)$ were significantly shorter than in good-risk patients, suggesting that the variables used are promising factors for predicting survival (Martini et al. 2020). However, prospective studies are needed to validate obesity as a factor to be taken into consideration in therapeutic choice.

\section{Conclusions}

Obesity is one of the main risk factors for the development of RCC. At the same time, several retrospective studies have shown that obesity appears to be a factor that positively influences the prognosis of patients with RCC. Actually, the available data about the predictive role of obesity are to be considered as a hypothesis generator. A challenge for the next future will be the planning of prospective studies which able to define the role of adipose tissue assessment as a prognostic factor in order to study its possible inclusion in the current prognostic models.

\section{Declaration of interest}

The authors declare that there is no conflict of interest that could be perceived as prejudicing the impartiality of this review.

\section{Funding}

This work did not receive any specific grant from funding agencies in the public, commercial, or not-for-profit sectors.

\section{References}

Albiges L, Hakimi AA, Xie W, McKay RR, Simantov R, Lin X, Lee JL, Rini BI, Srinivas S, Bjarnason GA, et al. 2016 Body mass index and metastatic renal cell carcinoma: clinical and biological correlations. Journal of Clinical Oncology 34 3655-3663. (https://doi.org/10.1200/ JCO.2016.66.7311)

Antoun S, Lanoy E, Albiges-Sauvin L \& Escudier B 2014 Clinical implications of body composition assessment by computed tomography in metastatic renal cell carcinoma. Expert Review of Anticancer Therapy 14 279-288. (https://doi.org/10.1586/14737140.20 13.866040)
C) 2021 Society for Endocrinology Published by Bioscientifica Ltd. Printed in Great Britain 
Aurilio G, Piva F, Santoni M, Cimadamore A, Sorgentoni G, LopezBeltran A, Cheng L, Battelli N, Nolè F \& Montironi R 2019 The role of obesity in renal cell carcinoma patients: clinical-pathological implications. International Journal of Molecular Sciences 205683. (https://doi.org/10.3390/ijms20225683)

Bergerot PG, Bergerot CD, Philip EJ, Meza L, Dizman N, Hsu J \& Pal SK 2019 Targeted therapy and immunotherapy: effect of body mass index on clinical outcomes in patients diagnosed with metastatic renal cell carcinoma. Kidney Cancer 3 63-70. (https://doi. org/10.3233/KCA-180047)

Bergström A, Hsieh CC, Lindblad P, Lu CM, Cook NR \& Wolk A 2001 Obesity and renal cell cancer - a quantitative review. British Journal of Cancer 85 984-990. (https://doi.org/10.1054/bjoc.2001.2040)

Boi SK, Orlandella RM, Gibson JT, Turbitt WJ, Wald G, Thomas L, Buchta Rosean C, Norris KE, Bing M, Bertrand L, et al. 2020 Obesity diminishes response to PD-1-based immunotherapies in renal cancer. Journal for ImmunoTherapy of Cancer $\mathbf{8}$ e000725. (https://doi. org/10.1136/jitc-2020-000725)

Calle EE \& Kaaks R 2004 Overweight, obesity and cancer: epidemiological evidence and proposed mechanisms. Nature Reviews: Cancer 4 579-591. (https://doi.org/10.1038/nrc1408)

Carnethon MR, De Chavez PJ, Biggs ML, Lewis CE, Pankow JS, Bertoni AG, Golden SH, Liu K, Mukamal KJ, Campbell-Jenkins B, et al. 2012 Association of weight status with mortality in adults with incident diabetes. JAMA 308 581-590. (https://doi.org/10.1001/jama.2012.9282)

Cho E, Adami HO \& Lindblad P 2011 Epidemiology of renal cell cancer Hematology/Oncology Clinics of North America 25 651-665. (https:// doi.org/10.1016/j.hoc.2011.04.002)

Choi Y, Park B, Jeong BC, Seo SI, Jeon SS, Choi HY, Adami HO, Lee JE \& Lee HM 2013 Body mass index and survival in patients with renal cell carcinoma: a clinical-based cohort and meta-analysis. International Journal of Cancer 132 625-634. (https://doi.org/10.1002/ijc.27639)

Choueiri TK, Xie W, Kollmannsberger CK, Rini BI, McDermott DF, Knox JJ $\&$ Heng DY 2010 The impact of body mass index (BMI) and body surface area (BSA) on treatment outcome to vascular endothelial growth factor (VEGF)-targeted therapy in metastatic renal cell carcinoma: results from a large international collaboration. Journal of Clinical Oncology 28 4524. (https://doi.org/10.1200/jco.2010.28.15_suppl.4524)

Choueiri TK, Powles T, Burotto M, Escudier B, Bourlon MT, Zurawski B, Oyervides Juárez VM, Hsieh JJ, Basso U, Shah AY, et al. 2021 Nivolumab plus cabozantinib versus sunitinib for advanced renal-cell carcinoma. New England Journal of Medicine 384 829-841. (https:// doi.org/10.1056/NEJMoa2026982)

Dai J, Zhang X, Liu Z, Song T, Zhu X, Zhang H, Wu M, Li X, Zeng H \& Shen P 2020 The prognostic value of body fat components in metastasis renal cell carcinoma patients treated with TKIs. Cancer Management and Research 12 891-903. (https://doi.org/10.2147/ CMAR.S230973)

Davoodi SH, Malek-Shahabi T, Malekshahi-Moghadam A, Shahbazi R \& Esmaeili S 2013 Obesity as an important risk factor for certain types of cancer. Iranian Journal of Cancer Prevention 6 186-194.

De Giorgi U, Procopio G, Giannarelli D, Sabbatini R, Bearz A, Buti S, Basso U, Mitterer M, Ortega C, Bidoli P, et al. 2019 Association of systemic inflammation index and body mass index with survival in patients with renal cell cancer treated with nivolumab. Clinical Cancer Research 25 3839-3846. (https://doi.org/10.1158/1078-0432. CCR-18-3661)

Fleischmann E, Teal N, Dudley J, May W, Bower JD \& Salahudeen AK 1999 Influence of excess weight on mortality and hospital stay in 1346 hemodialysis patients. Kidney International 55 1560-1567. (https://doi.org/10.1046/j.1523-1755.1999.00389.x)

Gan CL \& Heng DYC 2020 New insights into the obesity paradox in renal cell carcinoma. Nature Reviews: Nephrology 16 253-254. (https:// doi.org/10.1038/s41581-020-0264-y)

Gao Q, Zheng J, Yao X \& Peng B 2015 Adiponectin inhibits VEGF-A in prostate cancer cells. Tumour Biology 36 4287-4292. (https://doi. org/10.1007/s13277-015-3067-1)
Goebell PJ, Müller L, Hübner A, Harich HD, Boller E, Koska M, Jänicke M, Marschner N \& RCC-Registry Group (Tumour Registry of Advanced Renal Cell Carcinoma) 2018 Body mass index as independent predictor of overall survival in patients with advanced renal cell carcinoma at start of systemic treatment-analyses from the German Clinical RCC-Registry. Urologic Oncology 36 470.e1-470.e9. (https://doi.org/10.1016/j.urolonc.2018.07.007)

Gong J, Maia MC, Dizman N, Govindarajan A \& Pal SK 2016 Metastasis in renal cell carcinoma: biology and implications for therapy. Asian Journal of Urology 3 286-292. (https://doi.org/10.1016/j.ajur.2016.08.006)

Greenlee H, Unger JM, LeBlanc M, Ramsey S \& Hershman DL 2017 Association between body mass index and cancer survival in a pooled analysis of 22 clinical trials. Cancer Epidemiology, Biomarkers and Prevention 26 21-29. (https://doi.org/10.1158/1055-9965.EPI-15-1336)

Gu W, Zhu Y, Wang H, Zhang H, Shi G, Liu X \& Ye D 2015 Prognostic value of components of body composition in patients treated with targeted therapy for advanced renal cell carcinoma: a retrospective case series. PLOS ONE 10 e0118022. (https://doi.org/10.1371/journal. pone.0118022)

Hakimi AA, Furberg H, Zabor EC, Jacobsen A, Schultz N, Ciriello G, Mikklineni N, Fiegoli B, Kim PH, Voss MH, et al. 2013 An epidemiologic and genomic investigation into the obesity paradox in renal cell carcinoma. Journal of the National Cancer Institute $\mathbf{1 0 5}$ 1862-1870. (https://doi.org/10.1093/jnci/djt310)

Heng DY, Xie W, Regan MM, Warren MA, Golshayan AR, Sahi C, Eigl BJ, Ruether JD, Cheng T, North S, et al. 2009 Prognostic factors for overall survival in patients with metastatic renal cell carcinoma treated with vascular endothelial growth factor-targeted agents: results from a large, multicenter study. Journal of Clinical Oncology $\mathbf{2 7}$ 5794-5799. (https://doi.org/10.1200/JCO.2008.21.4809)

Horiguchi A, Asano T, Asano T, Ito K, Sumitomo M \& Hayakawa M 2008 Fatty acid synthase over expression is an indicator of tumor aggressiveness and poor prognosis in renal cell carcinoma. Journal of Urology 180 1137-1140. (https://doi.org/10.1016/j.juro.2008.04.135)

Horiguchi A, Asano T, Asano T, Ito K, Sumitomo M \& Hayakawa M 2008 Pharmacological inhibitor of fatty acid synthase suppresses growth and invasiveness of renal cancer cells. Journal of Urology 180729 736. (https://doi.org/10.1016/j.juro.2008.03.186)

Hursting SD \& Dunlap SM 2012 Obesity, metabolic dysregulation, and cancer: a growing concern and an inflammatory (and microenvironmental) issue. Annals of the New York Academy of Sciences 1271 82-87. (https://doi.org/10.1111/j.1749-6632.2012.06737.x)

Kaneko G, Miyajima A, Yuge K, Yazawa S, Mizuno R, Kikuchi E, Jinzaki M \& Oya M 2015 Visceral obesity is associated with better recurrence-free survival after curative surgery for Japanese patients with localized clear cell renal cell carcinoma. Japanese Journal of Clinical Oncology 45 210-216. (https://doi.org/10.1093/jjco/hyu193)

Khojandi N, Kuehm LM, Piening A, Donlin MJ, Hsueh EC, Schwartz TL, Farrell K, Richart JM, Geerling E, Pinto AK, et al. 2021 Oxidized lipoproteins promote resistance to cancer immunotherapy independent of patient obesity. Cancer Immunology Research 9214 226. (https://doi.org/10.1158/2326-6066.CIR-20-0358)

Labadie BW, Liu P, Bao R, Crist M, Fernandes R, Ferreira L, Graupner S, Poklepovic AS, Duran I, Maleki Vareki S, et al. 2019 BMI, irAE, and gene expression signatures associate with resistance to immune-checkpoint inhibition and outcomes in renal cell carcinoma. Journal of Translational Medicine 17 386. (https://doi.org/10.1186/s12967-019-02144-7)

Ladoire S, Bonnetain F, Gauthier M, Zanetta S, Petit JM, Guiu S, Kermarrec I, Mourey E, Michel F, Krause D, et al. 2011 Visceral fat area as a new independent predictive factor of survival in patients with metastatic renal cell carcinoma treated with antiangiogenic agents. Oncologist 16 71-81. (https://doi.org/10.1634/theoncologist.2010-0227)

Lalani AA, Xie W, Flippot R, Steinharter JA, Harshman LC, McGregor BA, Heng DYC \& Choueiri TK 2019 Impact of body mass index (BMI) on treatment outcomes to immune checkpoint blockade (ICB) in metastatic renal cell carcinoma (mRCC). Journal of Clinical Oncology 37 566. (https://doi.org/10.1200/JCO.2019.37.7_suppl.566) 
Lauby-Secretan B, Scoccianti C, Loomis D, Grosse Y, Bianchini F, Straif K \& International Agency for Research on Cancer Handbook Working Group 2016 Body fatness and cancer - viewpoint of the IARC Working Group. New England Journal of Medicine 375 794-798. (https://doi.org/10.1056/NEJMsr1606602)

Liu X, Guo L, Xiao K, Zhu W, Liu M, Wan R \& Hong K 2020 The obesity paradox for outcomes in atrial fibrillation: evidence from an exposure-effect analysis of prospective studies. Obesity Reviews 21 e12970. (https://doi.org/10.1111/obr.12970)

Mano R, Hakimi AA, Zabor EC, Bury MA, Donati OF, Karlo CA, Bazzi WM, Furberg H \& Russo P 2014 Association between visceral and subcutaneous adiposity and clinicopathological outcomes in non-metastatic clear cell renal cell carcinoma. Canadian Urological Association Journal 8 E675-E680. (https://doi.org/10.5489/cuaj.1979)

Martini DJ, Liu Y, Shabto JM, Carthon BC, Hitron EE, Russler GA, Caulfield S, Kissick HT, Harris WB, Kucuk O, et al. 2020 Novel risk scoring system for patients with metastatic renal cell carcinoma treated with immune checkpoint inhibitors. Oncologist $\mathbf{2 5}$ e484-e491. (https://doi.org/10.1634/theoncologist.2019-0578)

Menendez JA \& Lupu R 2007 Fatty acid synthase and the lipogenic phenotype in cancer pathogenesis. Nature Reviews: Cancer 7 763-777. (https://doi.org/10.1038/nrc2222)

Mittal B 2019 Subcutaneous adipose tissue and visceral adipose tissue. Indian Journal of Medical Research 149 571-573. (https://doi. org/10.4103/ijmr.IJMR_1910_18)

Mizuno R, Miyajima A, Hibi T, Masuda A, Shinojima T, Kikuchi E, Jinzaki M \& Oya M 2017 Impact of baseline visceral fat accumulation on prognosis in patients with metastatic renal cell carcinoma treated with systemic therapy. Medical Oncology 3447. (https://doi.org/10.1007/s12032-017-0908-3)

Motzer RJ, Mazumdar M, Bacik J, Russo P, Berg WJ \& Metz EM 2000 Effect of cytokine therapy on survival for patients with advanced renal cell carcinoma. Journal of Clinical Oncology 18 1928-1935.

Motzer RJ, Tannir NM, McDermott DF, Arén Frontera O, Melichar B, Choueiri TK, Plimack ER, Barthélémy P, Porta C, George S, et al. 2018 Nivolumab plus ipilimumab versus sunitinib in advanced renal-cell carcinoma. New England Journal of Medicine 378 12771290. (https://doi.org/10.1056/NEJMoa1712126)

Motzer RJ, Penkov K, Haanen J, Rini B, Albiges L, Campbell MT, Venugopal B, Kollmannsberger C, Negrier S, Uemura M, et al. 2019 Avelumab plus axitinib versus sunitinib for advanced renal-cell carcinoma. New England Journal of Medicine 380 1103-1115. (https:// doi.org/10.1056/NEJMoa1816047)

Motzer R, Alekseev B, Rha SY, Porta C, Eto M, Powles T, Grünwald V, Hutson TE, Kopyltsov E, Méndez-Vidal MJ, et al. 2021 Lenvatinib plus pembrolizumab or everolimus for advanced renal cell carcinoma. New England Journal of Medicine 384 1289-1300. (https:// doi.org/10.1056/NEJMoa2035716)

Naya Y, Zenbutsu S, Araki K, Nakamura K, Kobayashi M, Kamijima S, Imamoto T, Nihei N, Suzuki H, Ichikawa T, et al. 2010 Influence of visceral obesity on oncologic outcome in patients with renal cell carcinoma. Urologia Internationalis 85 30-36. (https://doi. org/10.1159/000318988)

Oreopoulos A, Padwal R, Kalantar-Zadeh K, Fonarow GC, Norris CM \& McAlister FA 2008 Body mass index and mortality in heart failure: a meta-analysis. American Heart Journal 156 13-22. (https://doi. org/10.1016/j.ahj.2008.02.014)

Renehan AG, Tyson M, Egger M, Heller RF \& Zwahlen M 2008 Bodymass index and incidence of cancer: a systematic review and metaanalysis of prospective observational studies. Lancet 371 569-578. (https://doi.org/10.1016/S0140-6736(08)60269-X)
Rini BI, Plimack ER, Stus V, Gafanov R, Hawkins R, Nosov D, Pouliot F, Alekseev B, Soulières D, Melichar B, et al. 2019 Pembrolizumab plus axitinib versus sunitinib for advanced renal-cell carcinoma. New England Journal of Medicine 380 1116-1127. (https://doi.org/10.1056/ NEJMoa1816714)

Romero-Corral A, Montori VM, Somers VK, Korinek J, Thomas RJ, Allison TG, Mookadam F \& Lopez-Jimenez F 2006 Association of bodyweight with total mortality and with cardiovascular events in coronary artery disease: a systematic review of cohort studies. Lancet 368 666-678. (https://doi.org/10.1016/S01406736(06)69251-9)

Sanchez A, Furberg H, Kuo F, Vuong L, Ged Y, Patil S, Ostrovnaya I, Petruzella S, Reising A, Patel P, et al. 2020 Transcriptomic signatures related to the obesity paradox in patients with clear cell renal cell carcinoma: a cohort study. Lancet: Oncology 21 283-293. (https://doi. org/10.1016/S1470-2045(19)30797-1)

Scelo G \& Larose TL 2018 Epidemiology and risk factors for kidney cancer. Journal of Clinical Oncology 36 JCO2018791905. (https://doi. org/10.1200/JCO.2018.79.1905)

Sharma A, Lavie CJ, Borer JS, Vallakati A, Goel S, Lopez-Jimenez F, Arbab-Zadeh A, Mukherjee D \& Lazar JM 2015 Meta-analysis of the relation of body mass index to all-cause and cardiovascular mortality and hospitalization in patients with chronic heart failure. American Journal of Cardiology 115 1428-1434. (https://doi.org/10.1016/j. amjcard.2015.02.024)

Steffens S, Grünwald V, Ringe KI, Seidel C, Eggers H, Schrader M, Wacker F, Kuczyk MA \& Schrader AJ 2011 Does obesity influence the prognosis of metastatic renal cell carcinoma in patients treated with vascular endothelial growth factor-targeted therapy? Oncologist 16 1565-1571. (https://doi.org/10.1634/ theoncologist.2011-0213)

Stone TW, McPherson M \& Gail Darlington L 2018 Obesity and cancer: existing and new hypotheses for a causal connection. EBiomedicine 30 14-28. (https://doi.org/10.1016/j.ebiom.2018.02.022)

Tanaka N, Mizuno R, Ito K, Shirotake S, Yasumizu Y, Masunaga A, Ito Y, Miyazaki Y, Hagiwara M, Kanao K, et al. 2016 External validation of the MSKCC and IMDC risk models in patients treated with targeted therapy as a first-line and subsequent second-line treatment: a Japanese Multi-Institutional Study. European Urology Focus 2 303-309. (https://doi.org/10.1016/j.euf.2015.11.001)

Tokunaga K, Matsuzawa Y, Ishikawa K \& Tarui S 1983 A novel technique for the determination of body fat by computed tomography. International Journal of Obesity 7 437-445.

Uretsky S, Messerli FH, Bangalore S, Champion A, Cooper-Dehoff RM, Zhou Q \& Pepine CJ 2007 Obesity paradox in patients with hypertension and coronary artery disease. American Journal of Medicine 120 863-870. (https://doi.org/10.1016/j.amjmed.2007.05.011)

Wang Z, Aguilar EG, Luna JI, Dunai C, Khuat LT, Le CT, Mirsoian A, Minnar CM, Stoffel KM, Sturgill IR, et al. 2019 Paradoxical effects of obesity on T cell function during tumor progression and PD-1 checkpoint blockade. Nature Medicine 25 141-151. (https://doi. org/10.1038/s41591-018-0221-5)

$\mathrm{Xu} \mathrm{H}$, Cao D, He A \& Ge W 2019 The prognostic role of obesity is independent of sex in cancer patients treated with immune checkpoint inhibitors: a pooled analysis of 4090 cancer patients. International Immunopharmacology 74 105745. (https://doi. org/10.1016/j.intimp.2019.105745)

Znaor A, Lortet-Tieulent J, Laversanne M, Jemal A \& Bray F 2015 International variations and trends in renal cell carcinoma incidence and mortality. European Urology 67 519-530. (https://doi. org/10.1016/j.eururo.2014.10.002)

Received in final form 22 April 2021

Accepted 5 May 2021

Accepted Manuscript published online 5 May 2021 https://erc.bioscientifica.com https://doi.org/10.1530/ERC-20-0457 (c) 2021 Society for Endocrinology Published by Bioscientifica Ltd. Printed in Great Britain 